\title{
anemon
}

Muş Alparslan Üniversitesi Sosyal Bilimler Dergisi

Journal of Social Sciences of Muş Alparslan University

Yı//Year: 2016 • Cilt/Volume: 4 • Sayı/Number: 2

ISSN: 2147-7655 • e-ISSN: 2149-4622

ÖZGÜN ARAŞTIRMA • ORIGINAL ARTICLE

\section{Firdevsü’l-İkbâl ve Özel Adlar}

\author{
Rabia Şenay ŞiŞMAN ${ }^{1, a}$ \\ ${ }^{1}$ Yrd. Doç. Dr., Muş Alparslan Üniversitesi, Eğitim Fakültesi, Türkçe Eğitimi Bölümü, Muş/ Türkiye \\ Başvuru tarihi: 08 Ocak 2016 Düzeltme tarihi: 07 Eylül 2016 Kabul tarihi: 29 Eylül 2016
}

Öz

Özel ad araştırmaların zenginleştirilmesi amacıyla hazırlanan bu yazıya konu olan malzemeler, Firdevsü'l-İkbâl adlı eserden alınmıştır. Orta Asya Türk tarihinin son dönemi ile ilgili yerli bir kaynak olan ve 19. asır sonu 20. asrın başlarında Harezm'de yazılan bu tarihî eserde coğrafi bilgiler; hanların yapmış oldukları askerî seferler, ava çıkışlarının anlatıldığı detaylandırılmış bilgiler mevcuttur. Siyaseti ve ekonomiyi konu edinmiş bir ürün olduğu hâlde hanlık sınırları içinde uygulanan imar politikaları kapsamında inşa edilen medreseler, camiler, kaleler, bağlar, köprüler gibi pek çok bina ile alakalı kayıt bilgilerinin de ele alındığg görülmüştür. Bunun yanında Hîve hanlığı yönetiminde faal bulunan resmî görevlerin bilgisi ile beraber bu görevlere kimlerin atandığ konusu eserde yer alan veriler arasındadır.

Firdevsü'l-İkbâl adlı 523 varaklık Çağatayca tarih kitabında geçen özel adların incelenerek tasnif edilmesinde amaç Klasik Sonrası Çağatay dili adı verilen Türk dilinin gelişim aşamalarından kabul edilen bir dönem hakkında yapılacak araştırmalara bir katkı sağlayabilme ve Türkçe'nin özel adlar konusundaki üretkenliğini çok da uzak olmayan bir geçmişten günümüze aksettirebilme çabasıdır. Çalışmamızda geçen adlandırmalarda özel adlar dikkate alınmış ve bu dil varlıklarına hem anlam hem gramer cephesinden bakılmıştır.

\section{Anahtar Kelimeler}

Özel Ad, Firdevsü’l-İkbâl, Hîve Hanlığı

\footnotetext{
a Sorumlu Yazar/Correspoding Author: Muş Alparslan Üniversitesi Kampüsü, Eğitim Fakültesi, Türkçe Eğitimi Bölümü, Diyarbakır Yolu 7. Km, 49250, Muş / Türkiye.

e-posta: rs.sisman@alparslan.edu.tr

doi : 10.18506/anemon.258559

URL: http://dergipark.gov.tr/anemon

Copyright (C 2013-2016 Muş Alparslan Üniversitesi
} 


\section{Firdaws al-Iqbal and Proper Names}

\section{Abstract}

The materials that are used in this text that is written with the aim of enrichment of proper noun researches are taken from the work called Firdaws al-Iqbal. In this historical work, there are detailed data about the geographical information, military expeditions of the khans and the stories about khans going hunting. Even though it is a study that treats the subject from political and economic aspects, there is also information about madrasahs, mosques, fortresses, vineyards, bridges and quasi buildings which were built under the conditions of zoning policies within the khanate borders and related records. Furthermore, this study also involves available information on all kinds of official duties and those who were assigned to these duties in the Khanate of Khiva.

The aim in examining and classifying the proper names that are mentioned in the Chagatai history book titled 'Firdaws al-Iqbal' consisting of 523 leaves is to contribute to the researches carried out on the era called 'Post Classical Chagatai' which is regarded as one of the developmental steps of Turkish language and to reflect the productivity of Turkish in terms of proper names from the recent past to present day. In the terminology of our study, proper names are noted and approached in terms of semantic and grammatical perspectives.

\section{Keywords}

Proper names, Firdaws al-Iqbal, the Khanate of Khiva.

\section{GIRIŞ}

Bir varlığı, kavramı, olguyu ya da şeyi adlandırma kalıcılığa, farklı kılmaya, belirgin hâle getirmeye hizmet eder. Adlandırmalarda kullanılan kelimeler, varlık ve nesnelere verilişlerine, bir diğer ifadeyle dilde yüklendikleri göreve göre özel ad ve cins ad olmak üzere ikiye ayrılır (Korkmaz, 2003: 200).

Ad, Türk Dil Kurumu'nca anlatan, tanımlayan, açıklayan, bildiren şeklinde nitelendirilirken, Korkmaz adı "evrendeki canlı cansız bütün varlıkları, insan tasavvurundaki somut ve soyut bütün kavramları tek tek ya da tür olarak karşılayan sözlerdir" şeklinde ifade etmiştir. Özel ad ise dar anlamıyla "tek bir kişiyi, belli bir canlı ya da cansız varlığı, bir düşünce ya da belli bir yeri anlatan adlar" olarak tanımlanmış ve özel adlar somut adlar içinde değerlendirilerek tek bir varlığın adı olan somut isimler özel ad kapsamında düşünülmüştür (Aksan, 1982: 94). Bununla beraber dilin kelimelerinden birinin, en sık olarak da bir tür adının, bir kişiye verilmesi onun özel ad sınıfına dâhil olması için yeterli görülmüştür (Aksan, 1982: 97).

Özel ad, dilin tür adı altında nitelendirilen genel söz varlıklarından bazılarının o dili konuşan kimi gruplarca farklı anlam bileşkelerinin dışında düşünülmesi ve bu şekliyle genel kullanımdan özel kullanıma indirgenmesi neticesi oluşmuş bir dil tasarrufudur. "Özel ad, ses ve heceden cümleye kadar herhangi bir dil biriminin anlam boşalmasına (asematication) uğratılarak kullanılmasıdır” (Karaağaç, 2009: 444). Cins ad ile ortak 
malzeme kullanımı dışında müşterek noktaları bulunmayan özel adların varlıklara tek tek ad olması niteliği, ayırt edici görev kapsamında sayılmıştır.

Göstergenin gösterilen ya da kavram yönünden yola çıkarak anlatımı, gösterilenin bağlandığı göstereni inceleyen dil bilim dalı demek olan ad bilim (Toklu, 2011: 116), özellikle özel ad şeklinde düşünülen kişi ve yer adlarını ile bu adlandırmalarda tesir derecelerine göre belirleyici olan faktörleri inceler.

Yer adları bilimi (toponymie), dağ adları bilimi (oronymie), su adları bilimi (hydronymie), kişi adları bilimi (antroponymie) gibi kısımlara ayrılan ad bilim dalı bilhassa kişi ve yer adları sahasında verimli sonuçlara ulaşan çalışmalar gerçekleştirmiştir (Sakaoğlu, 2001: 10)

Özel kılınan, tek olan varlıkları gösteren, işaret eden adların başta geleni olan özel adlar kökenleri bakımından farklı oluşum aşamalarına ve anlamları yönünden türlü etkilere maruz kalmış sözcükler olup adlandırma amacıyla kullanılırken rastgele seçilmiş imgeler şeklinde tasarlanmış değillerdir. Onlar, birey tarafından tüm somut ve ahlaki kişiliğin yansıması olarak algılanır, sosyal bağlamda anlam kazanan statü, saygınlık ve çeşitli sosyo-kültürel yapılanmaları da belirtir (Emecan, 1998: 366). Bu sebepten halkbilimciler adı "insanın toplumsal ve bireysel kişiliğinin yanı sıra büyüsel ve gizemsel gücünü de belirten bir simge" olarak tanımlamaktadırlar (Örnek, 1977: 148). Bu itibarla adlar çağrışım değeri mühimsenmiş dil birimleridir.

Kapsadığı bu duyusal kimlikten olsa gerek ad dağarcığı, bir milletin kültürünü yansıttığ derecede bireyin dünyasında da bir değer taşır. Dolayısıyla özel adlar özel tasarımlara, özel çağrışımlara yol açabileceği gibi, kişiye özgü duygu değerinin de taşıyıcısı durumundadır (Aksan, 2007: 96, 115).

Kültür araştırmalarını ilgilendiren çalışmalarda dil dizgesi içinde düşünülen birer birim olarak ele alınıp incelenmekte olan özel adlar, geçmiş ve günümüz zihniyetinin belirgin bir yansıması kabul edildiğinden, bilhassa şahıs adlarının araştırılmasının dil bilimi, tarih, sosyoloji, folklor, etnografi ve başka bilim alanları açısından çok önemli bulunduğu şüphesizdir (Memmedli, 1994: 95).

Ad seçiminin temelinde yatan dinsel, büyüsel, toplumsal inanç ve tasarımları saptama ve değerlendirme gibi unsurları tetkik eden ad bilimi bir yönüyle de kimi sözcüklerdeki ses ve biçim değişmelerini ilgilendiren dil olaylarının canlı delili hükmündedir (Acıpayamlı, 1992: 37). Arapça Sirâcu'd-devle adının İngilizcede Sir Roger Dowler şeklinde olması gibi (Palmer, 1882).

\section{KISŞi VE KAVIM ADLARI}

Ad verme geleneğinin oluşmasında toplumların kültür tarihleri, birbiriyle olan etkileşimleri, bağlı bulundukları dini, siyasi, sosyal ve kültürel çevreleri, sosyo-ekonomik yapıları etkilidir (Yalçıner, 2004: 3119). Toplumdan topluma değişebilen bu çevre ve yapılardan olsa gerek ad verme toplumlar arasında çeşitlilik gösteren uygulamalarla gerçekleşir. Bir başka deyişle ad koyma bir toplumun kültür geçmişine ve sosyal değişimlere bağlı bir hüviyet taşır. 
Yeni doğan çocuğa, kulağına ezan okuma suretiyle ad koyma İslam toplumunda süregelen mühim bir gelenektir. Öte yandan İslam öncesi Araplarda putların makamına ihtiramda bulunarak bebeğe isim verme bu geleneğin arkaik şekli olarak anılır. İdrak edilen zamanlar arası sosyal-kültürel farklılık, ad vermenin etkin rolü üzerinde değil de şekil ile ilgili kısmında tesir edici olmuştur. Orhan Şaik, tarafından Oğuz Kağan Destanı'nda, çocuğa, bir yaşına erdikten sonra bir toy yapılarak adın, bu törene katılan beylerce konduğunun dile getirilmesinde yine sözü edilen etkinin tespiti kaçınılmazdır (Gökyay, 2007). Bununla beraber Türklerde eskiden uygulanan âdetlerden biri de çocuğa, doğum sonrası, lohusanın kendine geldiğinde ilk gördüğü ne ise onun adının verilmesi şeklindedir. İslamiyet’ten sonra da eski ad verme geleneklerinin devam ettiğini gösterir örneklerin sayısı küçümsenmeyecek miktardadır. İslamiyet sonrasında Altay Türkleri arasında lohusa odasına ilk giren kimseye ait ismin çocuğa ad olması geçmişteki uygulamanın az da olsa değişerek devam durumuna misal teşkil eder niteliktedir (Gayretullah, 1963; Ràsonyi, 1963: 78). Bütün bu örneklerin bizi ulaştırdığı, ad verme sadece bizim kültürümüzde değil diğer dünya halklarının kültürlerinde de önemli folklorik bir öğe olup halk bilim çalışmalarının vazgeçilmez zenginlikteki malzemesi hükmünde görüldüğüdür.

Fark edileceği üzere adlandırmalarda toplumlar arasında geçerliliği kabul bulan uygulamalar genel çizgiler taşır: Dini ad kullanma; ünlü, saygı duyulan kimselerin ya da aile büyüklerinin adını alma (sosyal yaptırım) (Okay 2000: 120); yer, kavim, boy adlarının adını alma; atfedilen göreve göre; koruyan (apotropaeon: kötü ruhları korkutan) adları (Caferoğlu, 1968) verme; anne ve babanın sevgi şefkatini gösteren küçük, değerli, güzel anlamındaki (hypochoristica Meñli, Ahıçuk, Kutluk gibi) adları kullanma; Allah'ın adlarını içine alan (Teofor Ugan gibi) adları verme (Sakaoğlu, 2001: 11) oğlanlara kız adlarını verme ya da kızlara oğlan adlarını verme; çocuğun istenmediğini, sevilmediğini göstermek için ad verme (Çağatay, 1962: 13) gibi adı pek çok unsurun belirleyici fonksiyonu, halkça benimsenen genel eğilimlerin paralelinde değişerek devam eder.

Elde edilen bulgular neticesinde, Türklerin adlandırmada yaşadıkları coğrafî şartları ve kültür dairesini yansıtan söz varlıklarının izinden ayrılmadığı ve dahil olunmuş medeniyetin duyarlılıklarına ya da tâbi olunan dünya görüşüne uygun değişimler yaşadığı görülmüştür (Gülensoy, 1994: 5).

Nitekim bu anlayışla oluştuğu varsayılan: Güçlü hayvan adları: Böri, Bugra vb. güzel görünüşlü hayvan adları: Kuş vb. coğrafi adlar; Teniz vb. kavim adları: Çigil vb. yön ve vakit adları: Batu, Küz, Tüñ vb. bitki adları Budag vb. değerli maden adları: Témür vb. gök cisimlerinin adları: Yulduz... renk adları: Sarı...(Gülensoy, 1999: 3) gibi somut cins isimler Firdevsü'l-İkbâl'de kullanılmış olan özel adlardan sadece birkaç tanesidir.

Türk dilinde ad vermede somut unsurların tesirli oluşunun yanında, millet hayatı boyunca yaşanılan farklı medeniyet algıları ve kültür değerleri etkisiyle yaşanan değişimlerin de payı olduğu bilinir bir gerçekliktir (Öztürk, 2004: 2346). Bu sebepledir ki tarihi kahraman ve siyasi liderle ilgili adlar, yatırlarla ilgili adlar, peygamberler ve yakınlarıyla ilgili adlar bu türden değişimler sonrasında hayat bulmuş adlandırmalardır denilebilir (Örnek, 1975).

Günümüz etnograf-dilci gezginlerinin ad verme âdetlerini göz önünde tutarak hazırlamış oldukları listeleri incelemiş olan Ràsonyi kişi adlarını tasniflendirdiği bir çalışmasında aşağıda yer verdiğimiz sıralamayı kullanmıştır (Ràsonyi, 1973: 73): 
(i) Totemistik adlar

(ii) Amaçlı adlar (ebeveynin dilekleriyle ilgilidirler; koruyucu olanlar; kötü ruhları yanıltma içindir, Allah adını kapsayan teofor niteliklidirler; uzun ömürlü, iyi karakterli ve mutlu olma niyeti taşıyanların yanında vücutla ilgili iyi özellikleri belirtenleri vardır. Görkemli adlar bu grupta yer alır.)

(iii) Tesadüfi Adlar (Yeni doğan çocuğun göze çarpan bir özelliği; doğumdan sonra ilk göze çarpan nesne adı; çadıra, odaya giren ilk kimse; meterolojik bir olay; mevsim, gün ve bayram günü; doğum zamanı (Sakaoğlu, 1994: 508); doğum yeri; yeni doğan çocuğun kaçıncı çocuk olduğu

(iv) Rütbe, unvan adları

(v) Ana baba duygularını anlatan adlar

(vi) Teofor adlar

(vii) Kişilere bağlı adlar (Ràsonyi, 1963: 78).

Kişi adları kültüre, inanışlara, sosyal değerlere ve politik yaklaşımları göre zaman içinde değişimler geçirmesi açısından çok yönlü incelemeye açık dil tanıklarıdır (Başgöz, 2004). Bu anlamda gerçekleştirilecek çalışmalar neticesi oluşan veri malzemesi Türkçenin yazın tarihi boyunca bu sahadaki zengin kelime yapımı kabiliyetini ispata hizmet edecektir.

Kişi adlarında kullanılan dil öğelerinin sınıflandırılmasındaki oluşumlar ve tarihi süreçler kavim adları için de aynıdır. Türk dilinin adlandırma alanındaki kültür dokusu her anlamda kişi adlarını etkilediği nispette kavim adlarını da etkilendiğinden her biri adına kullanılan kriter diğeri için de uygun bulunmuştur. Nihayetinde birbiriyle ilgili bu adların veriliş mantığı ortak bir duyuş ve düşünüşün ürünüdür (Gülensoy, 1999: 8).

\section{RÜTBE VE UNVAN ADLARI}

Adlarla karşımıza çıkan rütbe ya da saygınlık ifade eden isimler şunlardır:

- $\quad$ Bég İleri gelen nüfuzlu kimse; sahip.

- $\quad$ Biy Bey

- Gazi (Ar.) Gaza eden.

- Hâca (Far.) Efendi, hoca, molla

- Han Emir

- Hanım (Han kelimesine gelen iyelik ekinin kalıplaşmasıyla) Kadın

- Hatun Sogd dilindeki ḩwťnh/hvaāten "kraliçe" sözünden Türk dillerine geçmiştir (Gabain, 1988).

- Sardar Kumandan

- $\quad$ Sultan < Arapça sulțān "Han” kelimesinin eş anlamlısıdır.

\section{YER ADLARI}

Coğrafya, bitki örtüsü ve yaşam koşullarıyla doğrudan ilgili bir unsur olduğundan yer adları bir milletin ortak hafizasında gizlide kalmış hatta bir anlamda efsaneleşmiş coğrafi, tarihi, siyasi meseleleri gün 1şı̆̆ına kavuşturacak nitelikteki söz varlıklarındandır. Halkın içinde yaşadığı çevreyi nasıl algıladığının tanığı olan yer adları aynı zaman da halkın 
gözlem ve tecrübelerinin bir sonucu olduğundan çeşitli bilim dallarının dikkatine layık bir çeşitliliği barındırır (Şenel, 2008).

Yer adlarıyla ilgili bir çalışmada adlandırma, tabiata ve fiziksel koşullara dayanan ile insanlara ve topluluklara dayanan adlar şeklinde iki ana bölüme ayrılmıştır (Başkan, 1989: 237). Bu iki bölüm kendi içinde üçer alt bölüme ayrılarak çevreyle (yönler, yer şekilleriyle ilgili olanlar, madenler, değerli taşlar, mevsimler, günler, sayılar renkler) ilgili adlar; bitkilerle ilgili adlar, hayvanlarla ilgili adlar; kişilerin fiziksel yaşayışı ile (yiyecek, içecek, eşya konacak kap, kesici araç, savaş aleti, kumaş maddeleri, yapıyla alakalı kısımlar) ilgili adlar, kişilerin duygusal yaşayışı ile (hisler, aile bireyleri ve dinle) ilgili adlar, kişilerin kendi varlıkları ile (vücut kısımları, rütbe ve mevki ve insana ait sıfatlar, mesleklerle) ilgili adlar şeklinde sınıflandırılarak yeni baştan çeşitli alt birimlere bölünmüştür.

Anlaşıldığı üzere bir anlamda çevremizde gördüğümüz ve algıladığımız her şeyin adıyla ilgilenen bilim demek olan onomastik ya da ad bilimin içinde bulunan özel adlar (Aksan, 2007: 1), herhangi bir ulusun dili kültürü, tarihi ve etnolojisiyle yakından ilgili tanıkları olduğundan geniş ölçüde araştırılmaya muhtaç gizidir (Aksan, 1969: 176). Önceleri bir dilin genel söz varlığının içinde yer almışken daha sonra çeşitli biçim ya da anlam değişiklikleri ile bu genel sıralamadan ayrılıp tek bir varlığa özgü hâle gelen özel adlar adına yapılan çalışmalar tarih, coğrafya, etnoloji, sosyoloji gibi bilim dallarını yeni ufuk açıcı sonuçlara götürecek ya da bu amaç doğrultusunda destekleyici bir verimliliğin sebebi olacak etkinliktedir.

$\mathrm{Bu}$ yöndeki araştırmaların zenginleştirilmesi adına atılmış adımlardan biri sayılabilecek bu yazıya konu olan, Özel Ad ile ilgili çalışma Orta Asya Türk tarihi son döneminin yerli kaynaklarından olan Firdevsü'l-İkbâl adlı 523 varaklık Çağatayca tarih kitabında geçen özel adların incelenerek tasnif edilmesidir. Klasik Sonrası Çağatay dili adı verilen Türk dilinin gelişim aşamalarından kabul edilen bir devir hakkında yapılacak araştırmalara küçük de olsa bir katkı sağlayabilme ve Türkçe'nin özel adlar konusundaki üretkenliğini çok da uzak olmayan bir geçmişten günümüze aksettirebilme çabası hedefimizi oluşturmaktadır.

Özel adlar açısından incelenen metin Hîve hanlığ 1 tarihinin kronolojik sıra ile anlatılan bu eser aynı zaman da Buhara, Hokand, İran ve Rusya ile olan diplomatik ilişkilerin de yer aldığı, Rusya ile Hîve hanlığı arasındaki devletler arası ticari münasebetin, hanlığa ödenen vergilerin de ele alındığ 1 siyaseti ve ekonomiyi konu edinmiş bir kaynaktır (Kahya, 2010; Kaman, 2012; Şişman, 2012).

Yine eserde bu devirde hanlık sınırları içinde uygulanan imar politikaları dahilinde inşa edilen medreseler, camiler, kaleler, bağlar, köprüler ve buna benzer binalar kaydedilmiş, eserin Hîve hanlığında mevcut olan her çeşit resmî görev ve bu görevlere kimlerin atandığı konusundaki bilgilere yer verilmiştir.

19. asır ve 20. asrın başlarında Harezm'de yazılan bu tarihî eserde coğrafi bilgiler de mevcuttur. Hanların yapmış oldukları askerî seferler, ava çıkışları günü gününe kaydedilmiştir. Bu coğrafyadaki nehirler, göller, çöller, bağlar, şehirler anlatılmıştır. Harezm özellikle Türkistan tarihinin çok yönlü kaynak eseri olma ayrıcalığı, metinde kullanılan dili de önemli kılmaktadır. 
Genel malzemeden türeme ve ancak bazı grupların özel ilgileriyle beraber varlık kazanması sonrası belirli bir zaman ve yer dilimine ait olma, özel adın tanımlanması adına umumi bir yaklaşımdır. Her dil için geçerli sayılabilecek bu yaklaşımın yanında özel adın tasnifi için öngörülen ölçütler her dilin içinde yer aldığı folklor, tarih ve kültür dairesine göre çeşitlilik sergilemektedir.

Çalışmamızda geçen özel adlar dikkate alınmış ve bu dil varlıklarına hem anlam hem gramer cephesinden bakılmıştır. Takip edilen yol, metinde geçen Türkçe kökenli olan ya da Türkçeleşmiş Türkçe olduğu halde, sonuna Türkçe ek almış özel adların tespiti ve bunların anlam ve yapı bakımından tasnifi şeklindedir. Sınıflandırmada önce kelime grupları dikkate alınmış ve tek kelime şeklinde olanlarla birleşik durumda olanlar en az iki kelimeden ve ikiden fazla kelimeden oluşan şeklinde ayrı tertip edilmiştir.

Bu çalışmanın kaynağını teşkil eden metinde geçen özel adlar içinde bulunan kişi adları sıralanırken var ise unvan, rütbe ya da boy adları yalnızca tek kelimelik sıralamalarda yer alan adlandırmalarda Abak (Sultan) olmak üzere parantez içinde ayrıca ifade edilmiştir. Sınıflandırılma öncesi metinde sıkça karşılaşılan rütbe ya da saygınlık ifadesi taşıyan sözcükler ayrıca ele alınmış olmakla beraber tek kelimelik kişi adları parantez içinde gösterilmiştir. Aynı kişi ile ilgili kullanılan ad eserin farklı yerlerinde iki ayrı şekilde kullanılmış ise bu durum Kutulmet (Bég) (Krş. Kutluk Muhammad Bég), Bérdi 'Alī (Krş. Berdalı) şeklinde belirtilmiştir. Kavim adları ve yer adları diziliminde de düzen aynı surette devam ettirilmiştir.

Belirlenen kelimeler ile kelime grupları, kök hâlindeki adlar ve ek seçimine göre adlar olmak üzere bu kez yapıca özellikleri dikkate alınarak dizilmiştir. Metnimizdeki sıralama yapılırken özel adlar, dildeki hazır malzemenin ayırt edici göreviyle yükümlü kullanımları varsayılmıştır (Ahmedov, 1991). Kişi adları tasnifinde yaşanan coğrafya ve yaşatılan törelerin önemsendiği dizilimlere dikkat edilmiş, rütbe ile saygı ifadesi taşıyan unvanlar sözü edilen tasniflerin başında ayrıca ifadelendirilmiştir. Metinde unvan ve rütbe adı olarak kullanımın yanında bazı yerlerde unvan veya rütbenin özel ada dahil olduğu örnekler de bulunmaktadır (Çın Gazi vb.).

\section{FİRDEVSÜ'L-İKBÂL'DE KELIMME VE KELIME GRUPLARI ŞEKLINNDEKİ ÖZEL ADLAR}

\subsection{Erkek Kişi Adları}

İzlenilen yöntem, Türkçe kökenli olan ya da Türkçeleşmiş Türkçe olduğu halde, sonuna Türkçe ek almış özel adların belirlenmesi ve bu söz varlıklarının anlam ve yapı bakımından sınıflandırılmasıdır. Tasnifte önce kelime grupları dikkate alınmış ve tek kelime şeklinde olanlarla birleşik durumda olanlar en az iki kelimeden ve ikiden fazla kelimeden oluşan tarzında iki ayrı başlık altında alfabetik bir sıra takip edilmek üzere bir araya getirilmiştir. Diğer adlandırmalarda da aynı düzene riayet edilmiştir.

\subsubsection{Tek Kelimeden Oluşan Erkek Kişi Adları}

Bu grupta 192 özel ad vardır. 
Abaka (Han), Abak (Sultan), Açay, Aganay (Han), Agaday, Agışı (Sultan), Ahıçuk, Akatay (Han), Akım (Han), Akman, Alanca (Han), Alkonut, Almanca (Han), Altan (Han), Argun (Han), Arslan (Han), Artuk (Han), Ata, Atlı (Han), Atsı (Han), Ay (Han), Aydak, Ayim (Bég), Aymir,

Baba (Bég), Bagır (Bég), Balbars, Baltaş (Bég), Barın, Barmak (Biy), Barscar, Bartan, Batu (Han), Baydar, Baydu (Han), Baysun, Begceday, Bégler (Han), Békiş, Belikeç (Sultan), Belkeday, Berdalı (Bég), Berdi (Biy), Bérdiş (Bég), Bölekey (Han), Börke (Han), Buçuga (Han), Budag̀, Bugra (Han), Buka (Han), Bulan (Biy), Bundaş, Buran, Burkay (Han), But, Buzancar (Han), Bürküt,

Cavçın, Cayılgan, Cumak (Bég), Cüci (Han), Çağatay (Han), Çakan, Çaksu, Çemişgezek (Bég), Çékli (Han), Çıntay, Çigil, Çın (Gazi), Çöngey (Biy),

Dönmes (Sardar), Durdı (Bég),

Ékilik (Biy), Élbar (Han), Élçigen, Élbars (Han), Élçi (Bég), Él (Han), Éşim (Biy), Éş (Sultan), Geldi (Han), Irkıl (Hâca), İmlak,

Kaban (Biy), Kaçulı, Kaçun, Kadan (Han), Kal (Han), Kalcıday (Han), Kalman, Kara (Han), Kara (Biy), Karaça, Karakçı, Karatay (Han), Karavul (Han), Katagan, Kavçın, Kaya (Han), Kaydu (Han), Kecek, Kedü (Han), Kerçek (Biy), Kepek (Sultan), Kıyan, Köçe, Köçenek (Biy), Kök, Koçaş, Kubday, Kuçan (Bég), Kudu, Kutluk (Biy), Kuvanç, Kün (Han), Kutulmet (Bég) (Krş. Kutluk Muhammad Bég), Kürley, Küskün (Han), Küz (Han),

Masav (Biy), Meñli (Han), Mönge (Han),

Nagday (Biy),

Oguz, Okubay, Ordu (Han),

Ögetey, Öz (Han), Özbek (Han),

Palak,

Saklap, Salcıday (Han), Salur, Sarman, Savçı, Sayın (Han), Sırtlan, Soyrı (Biy), Söyünç, Süyündük (Bég), Süyün (Biy),

Tag (Han), Tagay (Béy), Talış (Bég), Tanak, Taşım (Biy), Tavkara (Bég), Tay (Biy), Taylak, Temüge, Témür (Biy), Téñiz (Han), Téveçi, Tevke (Han), Tilev, Togrul (Han), Togul, Tokay, Toktagu (Han), Toktav, Tubulga (Biy), Tugaçar, Tölegen, Töre (Bég), Töşekçi, Tursun (Han), Tüken, Tüñ, Türk,

Ugan (Sultan), Umbay, Usta, Uranc1 (Han),

Yagma, Yahşılık (Biy), Yalabca (Han), Yalañtuş, Yarlıkap (Bég), Yamança (Biy), Yarma, Yarlıkab (Bég), Yaylak, Yazır, Yesügey, Yılım (Krş. Nıyaz Bég), Yolış, Yulduz (Han), Yumrı (Biy), Yuşumut. 


\subsubsection{En Az İki Kelimeden Oluşan Erkek Kişi Adları}

Tek kelimeden oluşan adlar dışında kalanlardır. İki kelime ile oluşmuş kişi adları daha çok birleşik ad görünümündedirler. Bu grupta 120 kişi adı mevcuttur.

Ağzı Kara, Arda Töre, Ata Çökgen, Atalık, Ay Dogdı (Bég), Aytan Töre, Baba Aksak, Balta Aka,

Balta Atalık, Baglan Ata, Baltaş Durman, Bartan Bahadur, Bay Böri (Han), Bat Kelki, Baysonkur, Bécen Kayan, Bekim Atalık, Bérdi 'Alī (Krş. Berdalı), Baylı Sardar, Begenç Bég, Bégi Sardar, Berdiş Atalık, Bérdi Bég (Han), Bég Turdı (Biy), Belgütey Ötçigin, Berdi Salur, Böri Bay, Börte Çene, Budan Kıyan, Bulcar Vaglan, Buskun Salcı, Büke Bindün, Bürgüt Bay,

Céren Kalmak, Cette Noyan (Krş. Cebe Noyan), Çitker Ürgenci, Ciyen Yomut, Cüci Buka, Cüci Kasar, Çarı Sardar, Çopan Sulduz, Çurlık Mergen,

Dey Noyan (Han), Dib Bakuy (Han), Dobun Bayan (Han), Dola Sardar, Dollı Teke, Dorc1 Tayş1, Dönmes Toksaba, Dutumenen (Han),

Él Keldi, Él Tüzer, Élçi Noyan, Érümçi Barlas, Éş Bol, Éş Témür,

Inanç Oglan, İ̃̃ Miñ, İşal, İt Burak (Han),

Kabay Şire, Kabu Buka, Kaka Sardar, Kapan Bay, Kara Köz, Karagay Kalmak, Kandım Sardar, Karagay Atalık, Katagan Yahşı, Keke Bay, Kel Yasavul, Keng Yantak, Kereyit Oñ (Han), Kılıç Cübeci, Kızıl Takır, Kızılbaş Hanları, Koçkar Ata, Koñrat Kuvandık, Koş Bérgen (Biy), Kotu Mengü, Koy Maral, Kök Köz (Biy), Kök Özekli (Biy), Kök Sardar, Közi Kiçik, Kuçum Bural, Kunduz Atalık, Kuş Bergen (Biy), Kün Dogdı, Kün Tugar,

Laçin Kalmak,

Mengübirti (Krş. Mengü Berdi), Mengü Temür (Han), Meñli Kéldi, Mergen Tayşı,

Ni 'mat Kereng, Nöküz Éş, Nokay Noyan,

Odur Bayan, Okça Töbe, Oraz `Ali, Orun Bay (Biy), Ökin Yarkak, Ötçigin Noyan, Öte Atalık, Ötemiş Atalık, Ötef Bay,

Saygundı Bay, Salcunay Üy, Salak Sardar, Sarıg Çavdur, Satıp Aldı (Bég), Sarıg Aygır, Suntay Témür, Süyek Kem,

Taşım Nayman, Témür Kürgen, Témür Taş, Ténri Berdi (Bég), Ténri Berdi (Biy)

Urak Bay, Yasugu Çaçan, Yav Basar (Bég), Yomut Berdi (Han), Yomut Kömek.

\subsection{3. İkiden Fazla Kelimeden Oluşan Erkek Kişi Adları}

İki veya daha fazla kelimeden oluşmuş kişi adları daha çok boy adı, rütbe adı gibi unsurlarla birlikte kullanıldığı gibi daha çok tamlama diye nitelendirebileceğimiz dil birlikleri hâlindedirler. Bu bölümde de 60 kişi adı mevcuttur. 
Abay Bég Göklen, At Kıran Bahadur, Ay Çuvak Töre,

Baba Çal Atalık, Baba On Bégi, Bay Kara Yüz Başı, Baylı Yüz Başı, Bég Turdı Tecen, Bégi Yüz Başı, Beki Yüz Başı, Berdi Bég Salak, Berdi Kaşka Yüzbaşı, Bérdi Kuş Bégi,

Ceren Yüz Başı, Ciyen Biy Yüz, Ciyen Kuş Bégi, Çon, Çong Kara Biy Keneges, Çong Kara Salur,

Él Kéldi Biy, Él Tüzer Bég, Ésen Bay Biy, Ésen Bay Kara Kalpak, Ésen Kéldi Biy, Ésen Atalık Bögeceli, Él Cigitey Noyan, Éş Bol Atalık, Éşim Yüz Başı,

(Kādır) Bergen Biy, Kandum Karavul Bégi, Kara Kalpak Bukan Biy, Kara Kalpak Töre Bég Kıyat, Kıyat Kara Kalpakī, Katta Bay Biy, Kavşuk Sardar, Kéldi Han Kör, Kıpçak Allaş Atalık, Kılıç Ak Kaş, Kıpçak Baba Daruga, Kıpçak Ésen Buga Çeçen, Koñrat (Krş. $<$ Moğ. Konggırat< Onggırat) Ésen Keldi, Koñrat Bég Kelle Késer, Kuş Yéter Kalmak, Kutlı Bay Kalmak,

Mankıt Ciyet Atalık, Mankıt Yav Böri,

Nöküz Bég Balta,

Öte (Kulı) Atalık, Ötef Berdi Atalık,

Salak Yüz Başı, Sarı Tay Biy, Télegen Yüz Başı, Töre Bég Kıyat, Töre Bég Yüz Başı, Yollı Bay Çavdur.

\subsection{Kadın Kişi Adları}

Eski Türk kültüründe erkek ve kadın kişi adları arasında ayrım belirsizdir. Çoğu kere bilhassa eski Türk dillerinde kadın kişi adları için "kadın, hatun, katun”; Arap dilinden alıntı "zevce, avrat, avret" gibi ismin arkasına hemen getirilen sözcüklerle ifade edilmekteydi (Varis, 2004: 124).

Kıza ad verme erkeğe ad verme kadar mühim görülmemesi sebebiyle olsa gerek, veriler erkek adına göre daha azdır. Şefkatli adların ya da duygu yansıtıcı kelimelerin verilmesi erkek adlara nispeten daha özgür olan bir seçimin sonucu olarak değerlendirilmektedir.

Firdevsü'l-İkbâl'deki kadın kişi adlarının durumu ve bunlarla ilgili malzemenin kategorisi erkek adları için tespit edilenden farklı değildir. Yulduz, Günhan, Aytan... gibi kimi isimler her iki cins için de kullanılmıştır. Cümle anlamından kadın kişi adı olduğunu belirlenmiştir.

Tek kelimeden oluşan kadın kişi adı şeklinde sadece Kadak örneğine rastlanmıştır. Bunun dışında iki kelimeden oluşan örnekler şu şekildedir:

Aruca Hatun, Tarakay Hatun, Tohta Hanım, Tüdekü Hatun.

İkiden daha fazla kelimeden oluşan kadın kişi adı olarak sadece Börte Kavçın Hatun örneği görülmüştür. 


\subsection{Kavim Adlar1}

Bu kategoride belirlenen kelimeler ile kelime grupları Kişi Ad'ında olduğu gibi tek kelimeden oluşan, en az iki kelimeden oluşan, ikiden fazla kelimeden oluşan kavim adı şeklinde sıralanmıştır.

\subsubsection{Tek Kelimeden Oluşan Kavim Adları}

Bu grupta 134 kelime mevcuttur.

Alak, Alaşa, Arabacı, Arık, Arulat, Aymak, Aynak, Baçkurlı, Baday, Bahrın (Kazak Türklerindendir), Balgalı, Başkır, Bayandır, Bayat (Oğuzların Bozok koluna bağlı boy), Bayraç, Bulgar, Burkut, Burmalı, Burlak, Buruncık, Burkaz, Cicüt, Çalcut, Çavdur, Çékli, Çerkes, Çıldır, Çırla, Çömekey, Durman, Égder, Elçigen, Érgeçlü, Ersarı (Krş. Érsarı), Éski, Geniges, Göklen, Gürgen, Gürlen, Halaç, İgdir, Kaçar, Kalmak (Krş. Kalmuk), Kancıgalı, Kañlı, Kanglık, Karadaşlı (Krş. Karadaşlu), Karlık, Kaşkaldaklı, Kaylı, Kazak, Kazalı, Kazılı, Kazuklı, Kégeyli, Kelekit, Kerki, Késekli, Kıpçak, Kıranç, Kırımsa, Kışlık, Kıyan, Kıyat, Kızılbaş, Kobu, Koçuk, Konklut, Koñrat, Kopalı, Korlas, Koşut, Kotur, Kozgan, Kökçe, Kökerdeli, Kulançı, Kuralas, Kuvang, Kuyang, Kuyucek, Kürkürevk, Kürel, Kürlevüt, Kürley, Mankıt, Mankışlak, Margaklı, Markay, Merkit, Meruçak, Meşekli, Mınazlı, Miñ, Mogul, Munçaklı, Narkız, Nayman, Nirun, Nöküz, Orus, Oymavut, Ögüz, Ötemiş, Özbek, Sagca, Sakar, Salak, Salur, Sarık, Saruk, Sart (Krş. Tacik), Sevgenli, Söyünçi, Südük, Süzenli, Tabın, Tacik (Harezm'in asıl yerlisi olup "Sart" kelimesinin eş anlamlısı olarak da kullanılır), Taraci, Tarhanlıg (Çağatay kabilesinden olma durumu), Tatar, Taycut, Teke, Tonkamar, Toktamış, Türkmen, Uşak (Yomut Türkmenleri), Uygur, Uymavut, Uyşun (Kazak Türklerindendir), Yantaklı, Yemreli (Bir Türkmen kavmi), Yomut, Yüz (Özbeklerin bir kolu).

\subsubsection{En Az İki Kelimeden Oluşan Kavim Adları}

Bu grupta 65 kavim adi mevcuttur.

Açamaylı Koñrat, Alan ve As, Ala Bölük, Aral Naymanı, Aral Nokuzı, Béş Arık, Béş Sarıg, Bögeceli Koñrat, Çandur Kıyatı, Cincel Uşak, Çonı Şaraf, Éş Kulı, Érümçi Barlas, Gürlenlik Nayman, İçki Salur, Kancıgalı Koñrat, Kara Çoka, Karaça Özbek, Kara Atlı, Kara Çoka, Kara Kalpak, Kaşkaldaklı Kak, Katıg Agaç, Keç Kıran, Kelte Baş, Kelte Çınar, Kırk Kayır, Kızıl Yılgun, Kızılça Deresi, Kiçik Bursuk, Kiçkine Darya, Koç Ata, Kopa Arıg, Koş Bulak, Koş Töfe, Koş Köprüklik, Koş Küprügi, Koş Tam, Koşa Çungul, Kök Özek, Kök Özekli, Kök Töpe, Köprükli Yaf, Közsiz Suyı, Kuçumlı, Kum Senger, Kuncud Yarma, Kuran Éli, Küren Korganı, Küren Tagı, Kürtiş Ata, Miñ Bulak, Nokay Éli, Orta Kuduk, Orus Kuşçı, Öküz Çülge, Salak Kırımsa, Sansız Kudukı, Soltı Kudukı, Söyünci Yolı, Tanga Hitay, Tört Kara, Tört Töpe, Uşak Urug, Üç Ok.

\subsubsection{Ikiden Fazla Kelimeden Oluşan Kavim Adları}

Bu grupta 20 kavim adı mevcuttur. 
Hitay Kara Kalpak (Krş. Hatay Kara Kalpak), Kara Han Teke, Kara Han Biy Teke, Kara Hanlı Teke, Kara Hanlıg Teke, Keneges Kara Kalpak, Koñrat Kara Kalpakıyya, Koñrat Koş Köprüki, Kök Öküz, Baba, Kuş Köprüklik Koñrat, Kul Yargan Nahrı, Kulan Kara Bag, Kuştamgalıg Nurtay Kara Kalpak, Nöküz Mankıt, On Tört Urug, Orta Yüz Kazak, Orun Bay Biy, Öküz Kétgen Nahrı, Şişli Kara Aygır, Taci Biy Kıyat.

\subsection{Yer Adlar1}

$\mathrm{Bu}$ kategoride belirlenen kelimeler ile kelime grupları kişi adlarında ve kavim adlarında olduğu gibi tek kelimeden oluşan, en az iki kelimeden oluşan, ikiden fazla kelimeden oluşan yer adı şeklinde sıralanmıştır

\subsubsection{Tek Kelimeden Oluşan Yer Adları}

Bu grupta 140 kelime mevcuttur.

Abıvard (Krş. Bavard), Adak, Agar, Atıl (Krş.Volga ya da İdil), Aybügür, Aygır, Baglan, Bakırgan, Balıklı, Balıklıg, Balkan (Krş. Semelkan), Basu, Baş, Başkard, Bayat, Béşikli, Bilgenli, Bosay, Böriçi, Buldımsar (Krş. Buldımsaz), Burlı, Burma, Buryaçı, Bürge, Çagatay, Çagıllı, Çalış (Amu Derya'nın koludur), Çamişgezek (Aladağ ve Balkan bölgelerine verilen ad), Çandır, Çapma, Çat, Çatlı, Çertekli, Çétli Suyı, Çılpuk, Çırla, Çilegen, Çizmandı, Çorçut, Çumanay, Çungul, Dargan, Darugan, Derrigez, Durgaduk, Durun, Élcik, Enek, Engerik, Ernek, Érsarı, Éşim, Fitnek, Gaznin (Krş. Gazne), Gögerçinlı (Krş. Gögerçinli), Gürlen, Güyük, Halaç, İşme, Kabaklı, Kahraman, Kakıştuvan, Kapkaklı, Kaplanlı, Karakum, Karnay, Katagan, Kazan, Késik, Kınak, Kökerdeli, Kulan, Kulançı, Kuvang, Kürdüş, Kürgen, Kürük, Mankışlak (Krş. Miñ Kışlak), Mankıt, Nayman, Nemeş, Ocarlı, Pisteli (Krş. Pıstalı), Saganç, Sakşın, Sayram, Sevgenli, Sunbar, Şagallar, Tallıg, Tallık, Tumarlı, Tankut (Tañut, Tübet), Tavkara, Tersek, Tın (Krş. Don), Torgavut, Tök, Tumarlı, Turbat, Tuzgan, Tuzlak, Tüñlükli, Ürgenç, Üsti, Üylük, Yantaklı, Yarmış, Yaska, Yaycı, Yayık, Yeñiçke (Krş. Yengiçke), Yilgınlı, Yumrı.

\subsubsection{En Az İki Kelimeden Oluşan Yer Adlart}

$\mathrm{Bu}$ grupta 157 yer adı vardır.

Acı Kak, Acı Kuduk, Ak Kaş, Ak Kır, Ak Köl, Ak Kum, Ak Öyrek, Ak Su, Ak Taş, Ak Töpe, Ak Yaf, Ak Yakış, Ak Yar, Ak Yaylak, Akça Tav, Akça Téngiz, Alaca, Ala Dag, Altı Töpe, Ar Tagı (Ulug Tag), Arık Balık, At Kéçü, At Yolı, Aygır Arıgı, Ayrı Tam, Bala Yatan, Balta Karga, Bék Töpe, Béş Arıg, Béş Arık, Béş Tam, Béş Töpe, Béş Sarıg, Biyik Tag, Böriçi Kırı, Böriçi Sengeri, Börili Köl, Büten Kamış, Bugra Han, Burya Baf, Çañlı Basu, Çaş Baba, Çekes Töpesi, Çertekli, Çılpuk, Çiçi Korganı, Çingiz Kırı, Çotak Kır, Çuçka Baş, Çukur Kum, Deli Kuduk, Dengiz Kuduk, Erken Kun (Krş. Keskin kemer), Ereng Kırı, Erengni Kırı, Han Balıg, Han Keçür (Krş. Han Keçuy), Isıg Köl, İltice Kudugı, Kakma Süksevül, Kañlı Kıpçak, Kara Aygır, Kara Baylı, Kara Buka, Kara Köl, Kara Kurum, Kara Müren, Kara Tal, Kara Tegelek, Kargalar Mahallası, Karabaş Kéçüy, Kara Kadak, Kara Sakal, Kara Su, Kara Tegelek, Kara Töpe, Kara Töpelik, Karaça Köl, 
Karık Köli, Karlı Çırla, Katıg Köl, Kavruk Tam, Keç Kıran, Kınak Kırı, Kınak Yolı, Kırk Kayrı, Kıyat Koñrat, Kiçik Tag, Koñrat Korganı, Koyçı Kayrı, Kök Ordu, Kök Özek, Kökçe Yolı, Kum Çüngül, Kum Yaska, Kubaş Yolı, Kul Yargan, Kuş Köl, Kuş Köprük, Kör Kudug, Kuş Töpe, Küyük Tam, Maylı Cungul, Megecik Köli, Mergen Kırılgan (Mergen: Tüfekli Asker), Miñ Bulak, Muz Gömgen, Nan Yémes, Şor Bulak, Şor Kak, Şor Köl, Şor Kuduk, Şor Kuyı, Taş Ayak, Taş Ayaklıg, Togrı Çang, Tumar Köl, Toñuz Sırtı, Turañgulı Baş, Turna Takırı, Ok Boyrı, Orta Kuduk, Ögüz Kétken, Özbek Yaf, Sarı Bay, Say Kéçü, Sırçalı Köli, Taş Köfrük, Ters Akar, Téve Boyun, Ulug Bursuk, Üç Acı, Üç Bölek, Üç Kersen, Üç Tagan, Üç Töpe, Üç Üzek, Üç Oçak, Üst Yurt (Krş. Ereng Kırı), Yalang Sengir, Yalangaç Kumı, Yaman Uygur, Yamgurlı Nahrı, Yañı Arık (Krş. Yañı Arıg), Yañı Yaf, Yartı Kum, Yayık Suyı, Yéti Yıgaç, Yılan Kırı, Yol Kudukı, Yuvan Suyı, Yügrük Baş.

\subsection{3. İkiden Fazla Kelimeden Oluşan Yer Adları}

Bu grupta 12 yer adı vardir.

Ak Taban Takır, Bala Koygan Töpe, Béş Sarıg Hıtay, Bütekeli Béş Töpe, Éş Bolay Köprüki, Kara Baylı Üzeki, Kara Şafak Kayırı, Kök Öküz Baba, Maylı Özek Nahrı, Teñri Yar Başı, Top Ayak Töpe, Top Atgan Töpe.

Firdevsü'l-İkbâl'de kullanılan özel adlandırmaları yapı yönünden incelememizde kök durumundaki adlar ve ek seçimine göre adlar şeklinde gruplandırılma tercihi yapılmıştır. Kişi adları kök-ek durumuna göre tasnif edilirken, isim soylu kök ya da gövdelerden sonra “+”; fiil soylu kök ya da gövdelerden sonra "." işareti ile belirtme yoluna gidilmiştir. Eklerin kelimelerdeki işlevleri, özel adlarda biçimce benzerlikten öteye gitmez. Ne de olsa özel adlar dilin saymaca (Karaağaç, 2009: 44) niteliğindeki birimleridir. Üstelik özel adlardaki değişim ve gelişim dinamikleri dilin kendi iç yapısından çok tarih, coğrafya, kavim ilişkileri gibi dil dışı kaynaklarla paralellik arz eder (Karaağaç, 2005: 67).

\section{KÖK-EK DURUMUNA GÖRE SINIFLANDIRMA}

\subsection{Firdevsü'l-İkbâl'de Kök Durumundaki Özel Adlar}

\subsubsection{Kök Durumundaki Kişi Adları}

Abak, Ata, Ay, Bagır, Batu, Bugra, Buka, But, Çın, Él, Éş, Kal, Kara, Kaya, Kök, Kün, Küz, Tag, Tay, Tüñ,

Bay Böri, Éş Bol, Kök Köz, Yav Bég.

\subsubsection{Kök Durumundaki Kavim Adları}

Miñ, Teke, Yüz,

Bék Töpe, Koç Ata, Koş Töfe, Tört Kara, Tört Töpe, Üç Ok,

Kara Han Teke, Kara Han Biy Teke. 


\subsubsection{Kök Durumundaki Yer Adları}

Baş, Bayat, Çat, Tın (Krş. Don), Tök,

Acı Kak, Ak Kır, Ak Köl, Ak Kum, Ak Su, Ak Taş, Ak Töpe, Ak Yaf, Ak Yar Ala Dag, Bék Töpe, Béş Tam, Béş Töpe, Bugra Han, Çaş Baba, Kara Köl, Karakum, Kara Müren, Kara Tal, Kara Töpe, Kara Su, Kuş Köl, Kuş Töpe, Şor Kak, Şor Köl, Sarı Bay, Üç Acı, Üç Töpe, Üst Yurt, Yañı Yaf, Yéti Yıgaç.

\subsection{Ek Seçimine Göre Özel Adlar}

$\mathrm{Bu}$ sınıflandırmada belirlenen kelimeler ile kelime grupları, ek seçimine göre düzenlenmiş olup yapıca özelliklerine dikkat çekilmek istenmiştir.

\subsubsection{Kişi Adları (Erkek-Kadın)}

-A: Dola (Sardar), Töre (Bég), Öte (Kulı),

-Ar: Él Tüzer, Kuş Yéter (Kalmak), Kün Tugar, Tugaçar,

-AnAk: Köçenek,

-ç: Kılıç, Kuvanç, Söyünç; Begenç Bey, Inanç (Oglan),

-da: Arda Töre,

-DI: Bérdi, Durd1, Geldi; Ay Dogd1; Beg Turd1, Kün Togd1, (Meñli) Kéldi, Mengübirti (Krş. Mengü Berdi), (Satıp) Aldı, Saygundı (Bay), Ténri Bérdi; Berdi Bég Salak, Kéldi Han Kör,

-DI-m: Kandim Sardar,

-dUk: Söyündük; (Koñrat) Kuvandık,

-dU-m: Kandum Karavul Bégi,

- $\dot{\mathrm{g}}$ : Budag,

-ĠA: (Baba) Daruga, Tubulga,

-(G)An: Bergen (Biy), Cayılgan, Katagan, Tölegen, Ugan; Ata Çökgen, Bergen Biy, Katagan Yahşı, Kuş Bergen, Témür Kürgen, Télegen Yüz Başı; -An: Bulan, Buran, Çakan, Kaban, Kapan, Kıyan, Kuçan, Tüken; Bécen Kayan, (At) Kıran (Bahadur),

-g்Ay: Yesügey; Karagay (Kalmak),

-ġu:Toktagu; Yasugu Çaçan,

-gun: Argun,

-I: Soyrı, Yumrı; (Katagan) Yahşı, 
-k: Aydak, Baba Aksak, Közi Kiçik,

-kUn: Buskun (Salc1), Küskün,

-m: Akım, Taşım,

-mA: Yagma, Yarma,

-mAK,: (Céren) Kalmak, (Karagay) Kalmak, (Laçin) Kalmak; Kuş (Yéter) Kalmak, (Kutlı Bay) Kalmak,

-mAn: Kalman, Sarman; Baltaş Durman,

-mAZ: Dönmes,

-mIş: Ötemiş (Atalık),

-n: Sayın,

-ng: Kereng,

-p /(-b): Saklap; Satıp (Aldı), Yarlıkab (Bég),

-r: Yazır,

-(s)Un: Tursun,

-ş: Bérdiş, Talış, Yolış,

-uk: Artuk; Kavşuk (Sardar),

-(u)l: Toğrul, Togul,

-(u)r: Salur,

-v: Tilev, Toktav,

-vul: Kandum Karavul, (Keke) Yasavul,

-(A)y: Açay, Aganay, Agaday, Kabay, Kürley, Salcıday, Tagay, Tokay,

+An: (Inanç) Oglan,

+Ça: Almanca, Karaça, Yalabca, Yamança; Okça Töbe; Aruca Hatun,

+ÇI: Élçi, Karakçı, Savçı, Téveçi, Töşekçi, Ürgenci; Buskun Salcı, Érümçi Barlas, (Kılıç) Cübeci,

+çuk: Ahıçuk,

+dUz: Sulduz, Yulduz,

+1 : Kızılbaş,

+1Ar: Bégler (Han),

+1I: Atlı, Baylı (Yüz Başı), (Atalık) Bögeceli, Çékli, Kaçulı; Baylı Sardar, Meñli (Kéldi);

Baylı Yüz Başı; Kutlı Bay (Kalmak), Yollı (Bay Çavdur),

+lIk: Atalık, Ékilik, Kutluk; Yahşılık; Atalık (Bögeceli), Baba Çal Atalık 
+m: Bekim (Atalık), Éşim (Yüz Başı),

+man: Akman,

+s1z: Ats1z,

+tay: Akatay, Karatay.

\subsubsection{Kavim Adlart}

-Aç: Halaç,

-(A)r: Salur, Kaçar,

-(G)An: Kul Yargan Nahrı, Öküz Kétgen Nahrı; -An: Keç Kıran,

-ç: Kiranç,

-k: Sarık, Saruk, Uşak; (Ala) Bölük,

-kI: İçki Salur,

-l: Kürel,

-mAk: Aymak,

-mAn: Durman,

-mIş: Ötemiş, Toktamış,

-mA: Kuncud Yarma,

-msA: (Salak) Kırımsa,

-n: Gürlen, Kozgan; Kuran Éli,

-ng: Kuvang, Kuyang,

-y: Kürley,

+Aç: Bayraç,

+cAk: Kuyucek,

+ÇA: Karaça Özbek,

+ÇI: Érümçi Barlas, Orus Kuşçı,

+cIk: Burunc1k,

+KInA: Kiçkine Darya,

+1 : Kizil (Y1lgun),

+lAK: Mangişlak,

+1I(G): Açamaylı (Koñrat), Baçkurlı, Balgalı; Burmalı, Çékli, Érgeçlü, Kanlı, Kancıgalı, Karadaşlı, Kaşkaldaklı, Kaylı, Kazuklı, Kégeyli, Kökerdeli, Kuçumlı, Sevgenli, Süzenli, Yantaklı, Yemreli;Tarhanlıg; Kara (Atlıg); Kuştamgalıg (Nurtay Kara Kalpak), 
+lIḲ: Kanglık, Karlık, Kışlık, Gürlenlik Nayman, Koş Köprüklik,

+mAn: Türkmen.

\subsubsection{Yer Adları}

-A: Adak,

-Ar: Ters Akar,

-ç: Saganç,

-I: Ayrı Tam, Togrı Çang,

-mA: Çapma,

-mAZ: (Nan) Yémes,

-n: Baglan,

-ng: Ereng Kırı, Yalang Sengir,

-ş: Çalış; Ak Yakış,

-(G)An: Katagan; (Mergen) Kırılgan; (Kul) Yargan, (Muz) Gömgen; (Bala) Koygan (Töpe), (Top) Atgan (Töpe); -An: Bala Yatan,

-(I)k: Kesik, Yayık; Biyik Tag, Karık Köli, Kiçik Tag, Yügrük Baş,

-mA: Kakma Süksevül,

-mIş: Yarmış,

-U: At Kéçü; Çañlı Basu,

-y: Éş Bolay Köprüki,

+Aç: Yalangaç Kumı,

+CIk: Élcik; Megecik Köli,

+ÇA: Akça (Tav), Akça Tengiz,

+ÇI: Böriçi, Buryaçı, Yaycı,

+l: Béşikli, Bilgenli,

+1AK: Tuzlak; Ak Yaylak,

+1Ar: Şagallar; Kargalar Mahallası,

+II: Çagıllı, Çatlı, Gögerçinlı, Kaplanlı, Kapkaklı, Tumarlı, Tüñlükli, Ocarlı, Yantaklı, Yılgınlı; Börili Köl, Çétli Suyı, Kañlı Kıpçak, (Kara) Baylı, Yamgurlı (Nahrı),

$+\mathrm{lI}(\dot{\mathrm{G}})$ : Balıklıg,

+lIḲ: Üylük, Tallık; (Kara) Töpelik,

+sIz: Közsiz Suyı, Sansız Kudukı, 


\section{SONUÇ}

Bu çalışmada Firdevsü'l-İkbâl'de geçen özel adlar anlam ve gramer nitelikleri dikkate alınarak incelenmiştir. Uygulanan metot, metinde geçen Türkçe kökenli olan ya da Türkçeleşmiş Türkçe olduğu halde, sonuna Türkçe ek almış özel adların tespiti ve bunların anlam ve yapıca tasnifidir. Sınıflandırmada önce kelime grupları dikkate alınmış ve tek kelime şeklinde olanlarla birleşik durumda olanlar en az iki kelimeden ve ikiden fazla kelimeden oluşan şeklinde üç grup şeklinde sıralanmıştır. Bu şekilde 900'e yakın kelime incelenmiştir. Bu incelemenin ardından belirlenmiş kelimeler ile kelime grupları ek seçimine göre adlar tarzında tasnif edilmiş ve yapı özellikleri dikkate alınmak istenmiştir.

Firdevsü'l-İkbâl'de kimi eklerde arkaik şeklin yanında yeni şeklin de çağdaş Özbekçenin etkisiyle tasarrufu söz konusudur (Şen, 2007: 1695). Bu tür eklerin her iki hâlinin de Çağataycanın son dönem eserlerinden olan metnimizde kullanılması sebebiyle ve Çağataycadan günümüz Özbekçesine geçiş aşamasındaki ek değişim aşamasını somutlandırmak adına, ekler tasnif edilirken bu iki şekillilik korunmuştur.

Ek seçimine göre yapılan çalışmada aşağıda sıralı eklerin kullanım sıklığının diğer eklere oranla daha çok olduğu tespit edilmiştir. Ek seçiminde Kişi Adı kategorisinde:

-DI: Bérdi, Durd1, Geldi; Ay Dogdı...

-( $\dot{\mathrm{G}})$ An: Bergen (Biy), Cayılgan, Katagan...

-mAK, Céren Kalmak, Karagay Kalmak...

-(A)y: Açay, Aganay...

+ÇI: Élçi, Karakçı, Savçı, Téveçi; Çékli, Kaçulı; Baylı Sardar, Meñli Kéldi...

+lIk: Atalık, Ékilik, Kutluk; Yahşılık...

Kavim Adı kategorisinde:

+1I(G): Açamaylı (Koñrat), Baçkurlı, Balgalı; Burmalı...

+1IḲ: Kanglık, Karlık, Kışlık, Gürlenlik Nayman...

Yer Adı kategorisinde:

-(G)An: Katagan; (Mergen) Kirılgan; (Kul) Yargan...

-(I)k: Kesik, Yayık; Biyik Tag, Karık Köli...

Netice itibariyle sözcükleri işleten, onları kullanım sahasına çıkartan manalı ya da vazifeli şekiller olan eklerdir. Ekler köklerden gövdeler yaparken aslında kökteki anlamı veya bu mevcut anlamın derecesini değiştirir. Dilin tarihî seyri içinde kök ve ekteki gerek kendi bünyesinde sese dayalı ya da analoji yolu ile yani başka şekillere benzetme sonrası ortaya çıkan değişimler gerekse kök ya da ekin işlekliğini yitirip büsbütün terk edilmesi gibi dil olayları karşısında metinlerin taranması yöntemiyle elde edilmiş malzeme, kelimenin kök ve ek dediğimiz şekillerinin yapısal ve anlamsal değişim süreçleriyle ilgili genel bilgilerimize özel dikkatler oluşturur. 
Öngörülen hedef dilin gelişimiyle ilgili klişe bilgiler yanında metne dayalı detayların örneklerini sayıca arttırmaktır. Her kelime ve ek muhakkak bu yolda atılmış önemli bir yapı taşıdır.

\section{KAYNAKÇA}

Acıpayamlı, O. (1992). Görenek ve Inançlar. Ankara: Kültür Bakanlığı Halk Kültürlerini Araştırma ve Geliştirme Genel Müdürlüğü Yayınları.

Ahmedov, T. (1991). Azerbaycan Toponimikasının Esasları. Bakı: Bakı Üniversiteti Neşriyatı

Aksan, D. (1969). X. Uluslararası Adbilimleri Kurultayı ve Düşündürdükleri. Türk Dili, 21(219), 176-178.

Aksan, D. (1982). Her Yönüyle Dil /Ana Çizgileriyle Dilbilim. Ankara: TDK Yayınları.

Aksan, D. (2007). Her Yönüyle Dil /Ana Çizgileriyle Dilbilim. Ankara: TDK Yayınları.

Başgöz, İ. (2004). Adlarımız ve Sosyal Değişim, TÜBA Günce, (31).

Başkan, Ö. (1989). Türkiye Köy Adları Üzerine Bir Deneme. Türk Dili Araştırmaları Ylllı̆̆l-Belleten, 237-251.

Caferoğlu, A. (1968). Filolojide İnsan ve Hayvan Soy birliği. Türk Dili Araştırmaları Ylllı̆g-Belleten, 1-15.

Çağatay, S. (1962). Türkçede 'kadın’ İçin Kullanılan Sözler. Türk Dili Araştırmaları Yillı̆g-Belleten,13-49.

Emecan, N. (1998). Türk Kişi Adlarının Değişen Sesi. Ankara: Dil ve Tarih Coğrafya Fakültesi Yayınları.

Gabain, A. V. (1988). Eski Türkçenin Grameri. (Çev.: Mehmet Akalın). Ankara: TDK Yayınlar1.

Gayretullah, H. B. (1963). Kazak Türklerinde Kişi Adları. Türk Kültürü, (10).

Gökyay, O. Ş. (2007). Dedem Korkudun Kitabı, İstanbul: Kabalcı Yayınları.

Gülensoy, T. (1994). Türklerde Ad Verme Geleneği ve Hektor. Millî Folklor, 3(22).

Gülensoy, T. (1999). Türk Kişi Adlarının Dil ve Tarih Açısından Önemi. Türk Dili, 1999/1 (565), 3-8.

Kahya, H. (2010). Mûnis ve Āgehî Firdevsü'l-İkbâl (vr. 1b-156b) (Giriş, Inceleme, Metin, Dizin). Yayınlanmamış Doktora Tezi. İstanbul: Marmara Üniversitesi Türkoloji Enstitüsü.

Kaman, S. (2012). Firdevsü'l-İkbâl (156b-336a) (Giriş, Transkripsiyonlu Metin, Inceleme, Dizin). Yayınlanmamış Doktora Tezi. İstanbul: Marmara Üniversitesi Türkoloji Enstitüsü.

Karaağaç, G. (2005). Dil, Tarih ve İnsan. Ankara: Akçağ Yayınları. 
Karaağaç, G. (2009). Türkçenin Söz Dizimi. İstanbul: Kesit Yayınları.

Korkmaz, Z. (2003). Türkiye Türkçesi Grameri (Şekil Bilgisi). Ankara: TDK Yayınları.

Memmedli, Y. (1994). Eski Türkçede Şahıs Adları ve Unvanları. Türk Dili Araştırmaları Yıllı̆̆g-Belleten, 95-110.

Okay, M. O. (2000). İnsanlığın Ortak Adları. Türk Dili Dil ve Edebiyat Dergisi, 2000/II(584), 120-125.

Örnek, V. S. (1975). Türk Folklorunda Ad Seçme ve Ad Koyma. İstanbul: Boğaziçi Üniversitesi Halk Bilim Yıllı̆̆

Örnek, V. S. (1977). Türk Halkbilimi. Ankara: Türkiye İş Bankası Kültür Yayınları.

Öztürk, J. (2004). Türkçede Ad Koyma Geleneğinde Değişimler. Ankara: Atatürk Kültür, Dil ve Tarih Yüksek Kurumu Yayınları.

Palmer, A. S. (1882). Folk-Etymology: A Dictionary of Verbal Corruptions or Words Perverted in Form or Meaning, by False Derivation or Mistaken Analogy. London: G. Bell and Sons.

Ràsonyi, L. (1963). Türklükte Kadın Adları, Türk Dili Araştırmaları Yıllı̆̆g-Belleten, 6387.

Ràsonyi, L. (1973). Türk Şahıs Adlarının Tasnifi. Türkoloji Dergisi, 1(1).

Sakaoğlu, S. (1994). Çocuklara Ad Konulmasında Görülen Yenilikler. Türk Dili, 1994/1(508), 275-282.

Sakaoğlu, S. (2001). Türk Ad Bilimi. Ankara: Türk Dil Kurumu Yayınları.

Şen, M. (2007). Tarihî Şivelerde Ek Uyumsuzluğu Var mı?. Ankara: Türk Dil Kurumu Yayınları

Şenel, M. (2008). Gaziantep İlinin Yakın Taşınmış Yer Adları. Uluslararası Gaziantep Araştırmaları (Sözlü Kültür, Dil ve Edebiyat) Sempozyumu, Gaziantep, 10-12 Nisan.

Şişman, R. Ş. (2012). Firdevsü'l-İkbâl (336b-523a) (Giriş, Transkripsiyonlu Metin, Inceleme, Dizin). Yayınlanmamış Doktora Tezi. İstanbul: Marmara Üniversitesi Türkoloji Enstitüsü.

Toklu, O. (2011). Dilbilime Giriş. Ankara: Akçă̆ Yayınları.

Varis, A. (2004). Türklerin Ad Koyma Gelenekleri Üzerine Bir İnceleme. Milli Folklor Üç Aylık Uluslar Arası Halk Bilimi Dergisi, 8(61), 124-133.

Yalçıner, N. (2004). Türkçede Son Çocuğa Verilen Adlar. Ankara: Atatürk Kültür, Dil ve Tarih Yüksek Kurumu Yayınları. 